\title{
Optimal Placement of Synchronous Condensers for Power Quality Improvement in Transmission System by Using Etap Power Station
}

\author{
Yadvinder Singh $^{1}$, Puneet Chopra ${ }^{2}$ and Ramandip Singh ${ }^{3}$ \\ ${ }^{1}$ Lecturer, Electrical Engineering Department, BGPC Sangrur, \\ ${ }^{2}$ Assistant Professor, Electrical Engineering Department, BGIET Sangrur, \\ ${ }^{3}$ Assistant Professor, Electrical Engineering Department, BGIET Sangrur,
}

\begin{abstract}
In my paper an attempt is made to improve the various parameters of a transmission system that will affect the power quality of the system. This is done by applying synchronous condensers in the system. In this thesis, we will consider an IEEE 14- bus data system for our simulation and work is done to find an optimum place to place our synchronous condenser to get the best results for reactive power, power factor and voltage drop. Simulation will be done to find various parameters by placing synchronous condenser at different buses and a comparison will be made by using ETAP PowerStation.
\end{abstract}

Keywords: Reactive power, Transmission Efficiency, Voltage Regulation, Power Quality, Transmission Losses, Natural Load.

\section{Introduction}

As the volume of power transmission and distribution increases, so do the requirement for a high quality and reliable supply. Thus, reactive power control and voltage control in an electrical power system is important for proper operation for electrical power equipment to prevent damage such as overheating of generators and motors, to reduce transmission losses and to maintain the ability of the system to withstand and prevent voltage collapse. As the power transfer grows, the power system becomes increasingly more complex to operate and the system become less secure. It may lead to large power with inadequate control, excessive reactive power in various parts of the system and large dynamic swings between different parts of the system, thus the full potential of transmission interconnections cannot be utilized. In power transmission, reactive power plays an important role. Real power accomplice the useful work while reactive power supports the voltage that must be controlled for system reliability. Reactive power has a profound effect on the security of power systems because it affects voltages throughout the system. Decreasing reactive power causes voltage to fall while increasing it causing voltage to rise. A voltage collapse may occur when the system tries to serve much more load than the voltage it can support. Voltage control and reactive power management are the two aspects of a single activity that both supports reliability and facilitates commercial transactions across transmission networks. Voltage is controlled by absorbing and generating reactive power. (B.R.Gupta, 1998)

When reactive power supply lower voltage, as voltage drops current must increase to maintain power supplied, causing system to consume more reactive power and the voltage drops further. If the current increase too much, transmission lines go off line, overloading other lines and potentially causing cascading failures. If the voltage drops too low, some generators will disconnect automatically to protect themselves. Voltage collapse occurs when an increase in load or less generation or transmission facilities causes dropping voltage, which causes a further reduction in reactive power from capacitor and line charging, and still there further voltage reductions. If voltage reduction continues, these will cause additional elements to trip, leading further reduction in voltage and loss of the load. The result in these entire progressive and uncontrollable declines in voltage is that, the system is unable to provide the reactive power required for supplying the reactive power demands. (Van CutsemT., 1991)

In general terms we can say that power quality of a transmission system is very essential. The problem of decreasing reactive power, voltage drop and power factor can be resolved by applying synchronous condensers in the given system. Synchronous condensers are used principally in large power applications because of their high operating efficiency, reliability, controllable power factor, and relatively low sensitivity to voltage dips. They are constant-speed machines with applications in mills, refineries, power plants, to drive pumps, compressors, fans and other large loads, and to assist in power factor correction. They are designed specifically for power factor control and have no external shafts, and are called synchronous condensers. In general, over excitation will cause the synchronous condenser to operate at a leading power factor, while under exercitation will cause the motor to operate at a lagging power factor. (C.L.Wadhwa, 2005) In this paper, we will consider an IEEE 14- bus data system for our simulation and work is done to find an optimum place to place our synchronous condenser to get the best results for reactive power, power factor and voltage drop. 
Simulation will be done to find various parameters by placing synchronous condenser at different buses and a comparison will be made by using ETAP PowerStation.

\subsection{Power Quality Analysis by Optimal Placement of Synchronous Condenser}

Synchronous motors load the power line with a leading power factor. This is often useful in cancelling out the more commonly encountered lagging power factor caused by induction motors and other inductive loads. Originally, large industrial synchronous motors came into wide use because of this ability to correct the lagging power factor of induction motors. This leading power factor can be exaggerated by removing the mechanical load and over exciting the field of the synchronous motor. Such a device is known as a synchronous condenser. Furthermore, the leading power factor can be adjusted by varying the field excitation. This makes it possible to nearly cancel an arbitrary lagging power factor to unity by paralleling the lagging load with a synchronous motor. A synchronous condenser is operated in a borderline condition between a motor and a generator with no mechanical load to fulfill this function. It can compensate either a leading or lagging power factor, by absorbing or supplying reactive power to the line. This enhances power line voltage regulation. Since a synchronous condenser does not supply a torque, the output shaft may be dispensed with and the unit easily enclosed in a gas tight shell. The synchronous condenser may then be filled with hydrogen to aid cooling and reduce windage losses. Since the density of hydrogen is $7 \%$ of that of air, the windage loss for a hydrogen filled unit is $7 \%$ of that encountered in air. Furthermore, the thermal conductivity of hydrogen is ten times that of air. Thus, heat removal is ten times more efficient. As a result, a hydrogen filled synchronous condenser can be driven harder than an air cooled unit, or it may be physically smaller for a given capacity. There is no explosion hazard as long as the hydrogen concentration is maintained above $70 \%$, typically above $91 \%$.

\subsection{Power Quality improvement by synchronous condenser}

The efficiency of long power transmission lines may be increased by placing synchronous condensers along the line to compensate lagging currents caused by line inductance. More real power may be transmitted through a fixed size line if the power factor is brought closer to unity by synchronous condensers absorbing reactive power. The ability of synchronous condensers to absorb or produce reactive power on a transient basis stabilizes the power grid against short circuits and other transient fault conditions. Transient sags and dips of milliseconds duration are stabilized. This supplements longer response times of quick acting voltage regulation and excitation of generating equipment. The synchronous condenser aids voltage regulation by drawing leading current when the line voltage sags, which increases generator excitation thereby restoring line voltage. (Figure below) A capacitor bank does not have this ability.

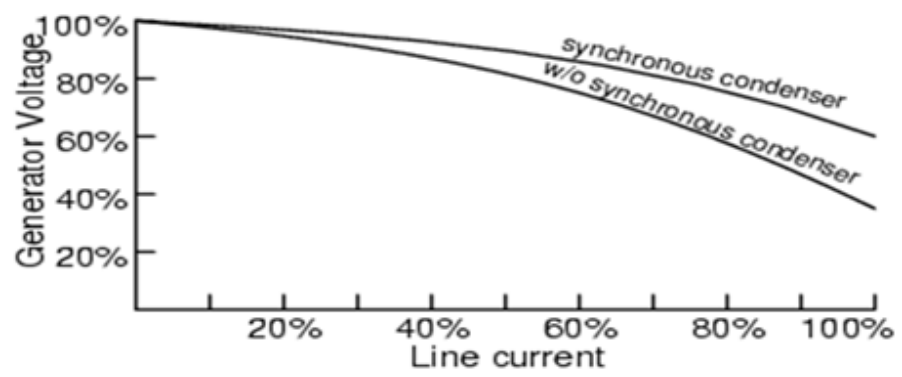

Figure 1: Synchronous condenser improves power line voltage regulation.

The capacity of a synchronous condenser can be increased by replacing the copper wound iron field rotor with an ironless rotor of high temperature superconducting wire, which must be cooled to the liquid nitrogen boiling point of $77 \mathrm{oK}(-196 \mathrm{oC})$. The superconducting wire carries 160 times the current of comparable copper wire, while producing a flux density of 3 Teslas or higher. An iron core would saturate at 2 Teslas in the rotor air gap. Thus, an iron core, approximate $\mu \mathrm{r}=1000$, is of no more use than air, or any other material with a relative permeability $\mu \mathrm{r}=1$, in the rotor. Such a machine is said to have considerable additional transient ability to supply reactive power to troublesome loads like metal melting arc furnaces. The manufacturer describes it as being a "reactive power shock absorber". Such a synchronous condenser has a higher power density (smaller physically) than a switched capacitor bank. The ability to absorb or produce reactive power on a transient basis stabilizes the overall power grid against fault conditions`(Power System Analysis, WCB McGraw Hill, 1999)

\subsection{Need for optimal placement of synchronous condenser}

Majority of loads in power systems use reactive power. In a power system, active power in several MWs is only generated by synchronous generators, while reactive power is produced not only by synchronous generator but also is injected by the other devices such as: Static VAR Compensator (SVC), Synchronous 
Condenser (SC), and Capacitor. Among these equipment's, capacitor has the slowest and stepped speed response while installation and operating costs of capacitor are considerably lower than the other reactive power sources. Synchronous condenser systems only supply reactive power.

This type of DG can improve the voltage profile by providing reactive power. The synchronous machine is considered as synchronous condenser when running without a mechanical load and it can either supply or absorb reactive power. DGs also participate in the voltage and frequency control. Depending on the load demand, the DGs can reduce the system losses and improve voltage profile in cases where they supply local customer. Distributed generations (DG) is related with the use of small generating units installed in strategic points of the electric power system and, mainly, closes to load centers. The sittings of DGs in distribution system have an important impact on the operations and control of power system. Non optimal placement and sizing of DGs can increase system losses, voltage flicker and costs. So, optimal placement of DGs can be very useful for the system operation. The planning of the electric system with the presence of DG requires the definition of several factors, such as: the best technology to be used, the number and the capacity of the units, the best location, the network connection way, etc.

The impact of DG in system operating characteristics, such as electric losses, voltage profile, reliability, among other, needs to be appropriately evaluated. The selection of the best places for installation of the DG units in large distribution systems is a complex combinatorial optimization problem. Due to placement of condenser at different buses active and reactive power losses decreases. (Nanjing. 2009) Due to placement of condenser, the reactive power supplied by the generator G1 reduces and thus the losses in the system also reduces. The condenser supplies the reactive power with the increasing reactive load and the losses are minimum, voltage profile also improves with the support of reactive power.

\subsection{ETAP PowerStation Simulator}

ETAP is the global market and technology leader in electrical power system modeling, design, analysis, optimization, control, operation, and automation software. The company has been powering success for nearly 30 years by providing the most comprehensive and widely-used enterprise solution for generation, transmission, distribution, industrial, transportation, and low-voltage power systems.

ETAP software provides engineers, operators, and managers a platform for continuous functionality from modeling to operation. ETAP's model-driven architecture enables 'Faster than Real-Time' operations where data and analytics meet to provide predictive behavior, pre-emptive action, and situational intelligence to the owner-operator.

At ETAP, we harness the thinking power and the passion of our engineers, scientists, and industry experts to transform the spark of ideas into products that can fuel the global economy. More power system experts trust ETAP for their most demanding projects.

\section{Case study for 14-bus system}

Firstly, various parameters of the system like power factor, voltage drop and reactive power will be observed without using condenser. Next a condenser will be placed in the system and change in the values of various parameters will be observed and compared. Change in the values of various parameters will be observed when condenser is placed at various buses in the system. Now an optimum place for the condenser will be searched to get best power quality results. Finally a comparison will be made between various parameters of the system to check for best optimum place for the condenser to get best power quality results in the system.

Through simulation we will be able to identify the various buses where we can place synchronous condenser and improve power quality of the system in the best way. In the presented 14 bus system problem, the power quality of system will be identified and improved through simulation. Generator G1 of $160 \mathrm{MW}$ is connected at bus 1 and G2 of $80 \mathrm{MW}$ is connected at bus 2. Different loads are connected at each bus. Transformer T1 of 100 MVA is connected between bus4 and bus9, 18, Transformer T2 of 100 MVA is connected between bus 4 and bus 9 and T3 of same rating is connected between bus 5 and bus 6 .

\subsection{System without Synchronous Condenser}




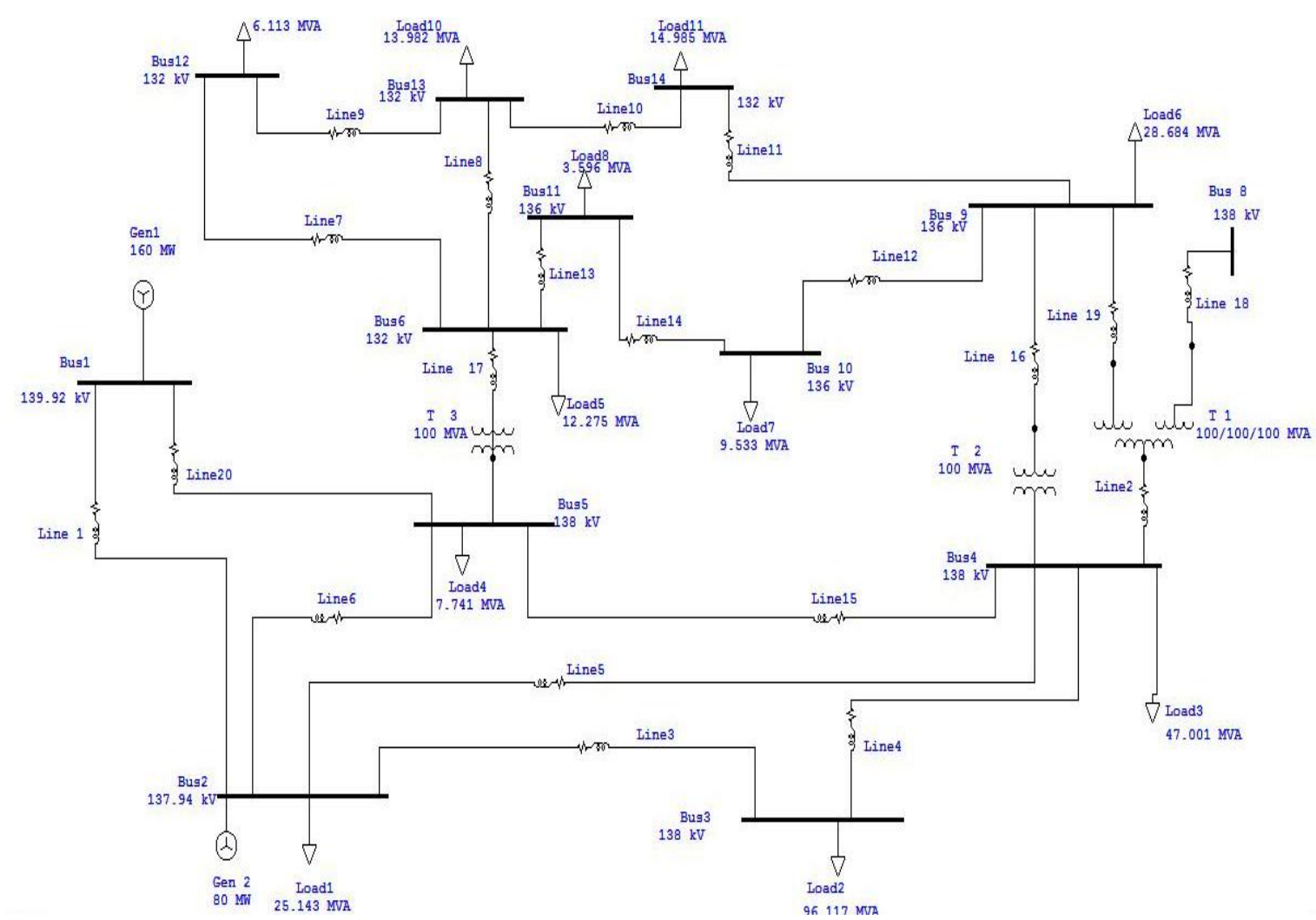

Figure 2: 14 Bus systems without synchronous condenser

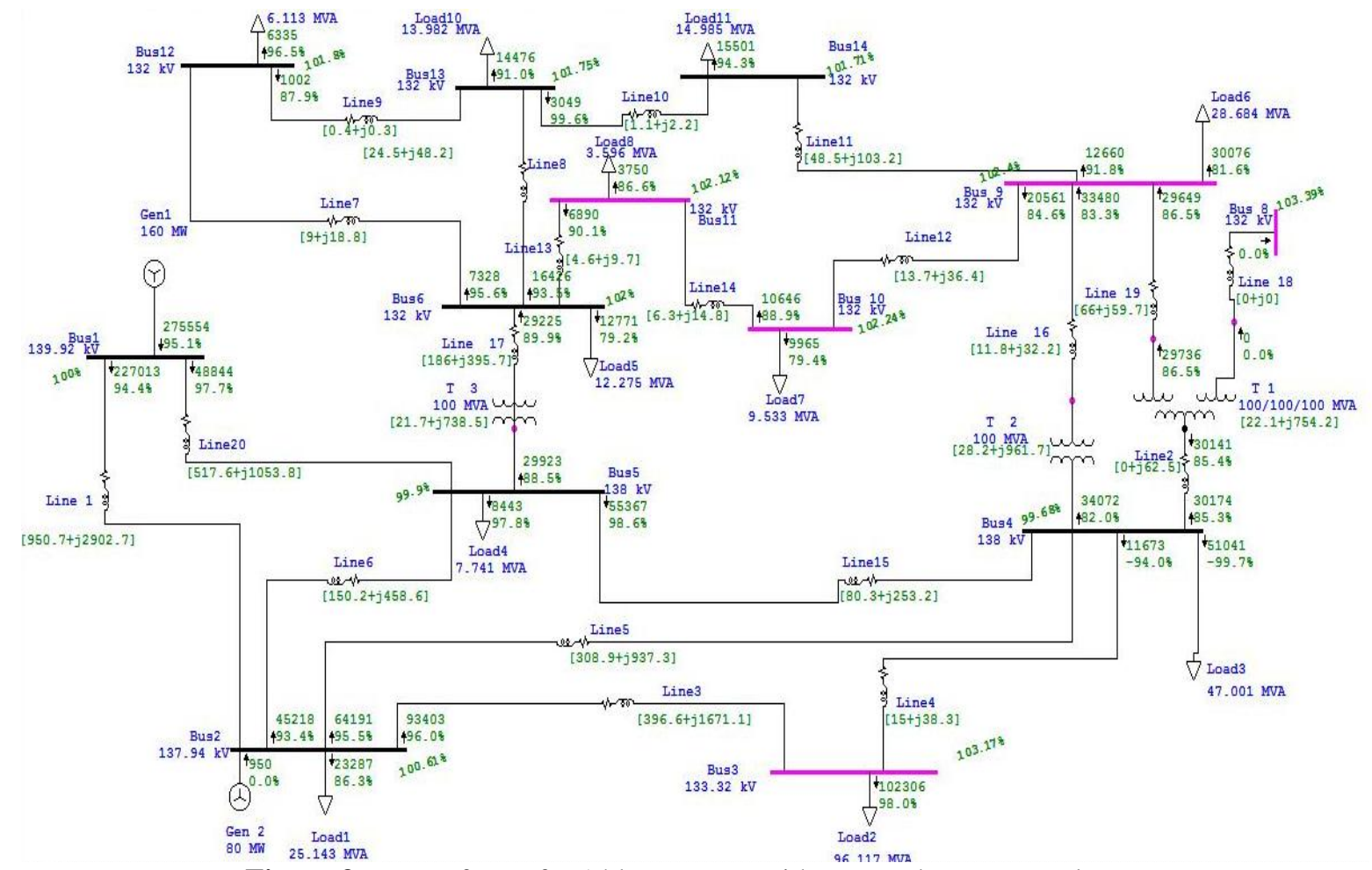

Figure 3: Power factor for 14 bus system without synchronous condenser 


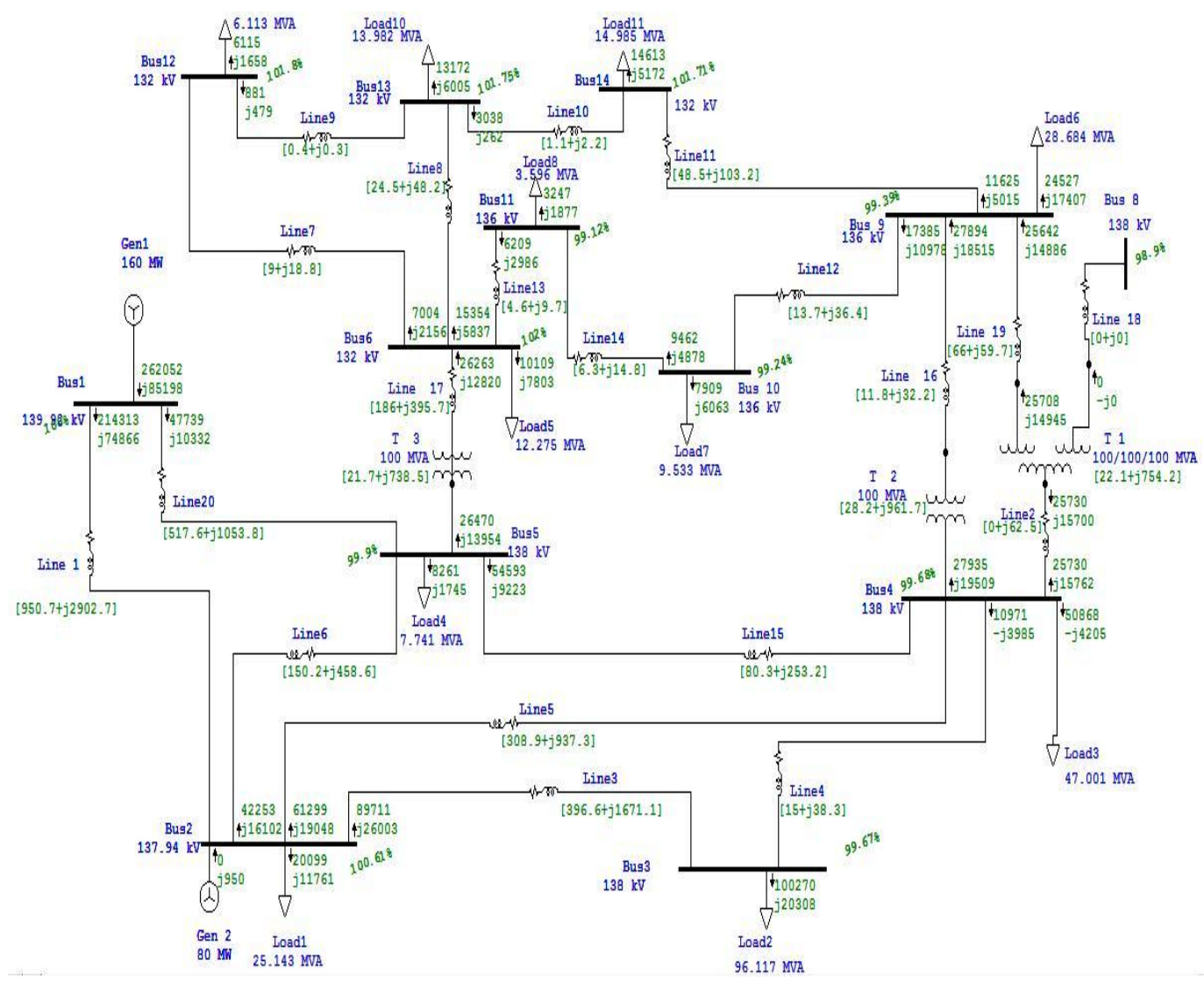

Figure 4: Line losses for 14 bus without synchronous condenser

Table 1: Bus data for 14 bus system

\begin{tabular}{|l|l|}
\hline Bus No. & Voltage(KV) \\
\hline Bus 1 & $\mathbf{1 3 9 . 9 2}$ \\
\hline Bus 2 & $\mathbf{1 3 7 . 9 4}$ \\
\hline Bus 3 & $\mathbf{1 3 3 . 3 2}$ \\
\hline Bus 4 & $\mathbf{1 3 8}$ \\
\hline Bus 5 & $\mathbf{1 3 8}$ \\
\hline Bus 6 & $\mathbf{1 3 2}$ \\
\hline Bus 7 & -- \\
\hline Bus 8 & $\mathbf{1 3 2}$ \\
\hline Bus 9 & $\mathbf{1 3 2}$ \\
\hline Bus 10 & $\mathbf{1 3 2}$ \\
\hline Bus 11 & $\mathbf{1 3 2}$ \\
\hline Bus 12 & $\mathbf{1 3 2}$ \\
\hline Bus 13 & $\mathbf{1 3 2}$ \\
\hline Bus 14 & $\mathbf{1 3 2}$ \\
\hline &
\end{tabular}

Table 2: Generator data for 14 bus system

\begin{tabular}{|l|l|}
\hline Generator No. & Power(MW) \\
\hline Gen1 & 160 \\
\hline Gen2 & 80 \\
\hline
\end{tabular}

Table 4.3: Transformer data for 14 bus system

\begin{tabular}{|l|l|}
\hline Transformer No. & Rating(MVA) \\
\hline T 1 & 100 \\
\hline T2 & 100 \\
\hline T3 & 100 \\
\hline
\end{tabular}

Table 4: Resistance data for 14 bus system

\begin{tabular}{|l|l|l|l|}
\hline Line No & From bus & To bus & Resistance \\
\hline 1 & 1 & 2 & 0.01938 \\
\hline 2 & 4 & 7 & 0 \\
\hline 3 & 2 & 3 & 0.04699 \\
\hline 4 & 3 & 4 & 0.06701 \\
\hline
\end{tabular}


Optimal Placement of Synchronous Condensers for Power Quality Improvement in Transmission..

\begin{tabular}{|l|l|l|l|}
\hline 5 & 2 & 4 & 0.05811 \\
\hline 6 & 2 & 5 & 0.05695 \\
\hline 7 & 6 & 12 & 0.12291 \\
\hline 8 & 6 & 13 & 0.06615 \\
\hline 9 & 12 & 13 & 0.22092 \\
\hline 10 & 13 & 14 & 0.17093 \\
\hline 11 & 9 & 14 & 0.12711 \\
\hline 12 & 9 & 10 & 0.03181 \\
\hline 13 & 6 & 11 & 0.09498 \\
\hline 14 & 10 & 11 & 0.08205 \\
\hline 15 & 4 & 5 & 0.01335 \\
\hline 16 & 4 & 9 & 0 \\
\hline 17 & 5 & 6 & 0 \\
\hline 18 & 7 & 8 & 0 \\
\hline 19 & 7 & 9 & 0 \\
\hline 20 & 1 & 5 & 0.05403 \\
\hline
\end{tabular}

Table 5: Reactance data for 14 bus system

\begin{tabular}{|l|l|l|l|}
\hline Line No & From bus & To bus & Reactance \\
\hline 1 & 1 & 2 & 0.05917 \\
\hline 2 & 4 & 7 & 0.20912 \\
\hline 3 & 2 & 3 & 0.19797 \\
\hline 4 & 3 & 4 & 0.17103 \\
\hline 5 & 2 & 4 & 0.17632 \\
\hline 6 & 2 & 5 & 0.17388 \\
\hline 7 & 6 & 12 & 0.25581 \\
\hline 8 & 6 & 13 & 0.13027 \\
\hline 9 & 12 & 13 & 0.19988 \\
\hline 10 & 13 & 14 & 0.34802 \\
\hline 11 & 9 & 14 & 0.27038 \\
\hline 12 & 9 & 10 & 0.0845 \\
\hline 13 & 6 & 11 & 0.1989 \\
\hline 14 & 10 & 11 & 0.19207 \\
\hline 15 & 4 & 5 & 0.04211 \\
\hline 16 & 4 & 9 & 0.55618 \\
\hline 17 & 5 & 6 & 0.25202 \\
\hline 18 & 7 & 8 & 0.17615 \\
\hline 19 & 7 & 9 & 0.11001 \\
\hline 20 & 1 & 5 & 0.22304 \\
\hline
\end{tabular}

Table 6: Load data for 14 bus system

\begin{tabular}{|l|l|}
\hline Load No. & Rating (MVA) \\
\hline Load1 & 25.143 \\
\hline Load2 & 96.117 \\
\hline Load3 & 47.001 \\
\hline Load4 & 7.741 \\
\hline Load5 & 12.275 \\
\hline Load6 & 28.684 \\
\hline Load7 & 9.533 \\
\hline Load8 & 3.596 \\
\hline Load9 & 6.113 \\
\hline Load10 & 13.982 \\
\hline Load11 & 14.985 \\
\hline
\end{tabular}

Table No 7: Line losses without synchronous condenser

\begin{tabular}{|l|l|l|l|}
\hline Line No & From bus & To bus & Losses \\
\hline 1 & 1 & 2 & $95.7+\mathrm{j} 2902.7$ \\
\hline 2 & 4 & 7 & $0+\mathrm{j} 625$ \\
\hline 3 & 2 & 3 & $396.6+\mathrm{j} 1671.1$ \\
\hline 4 & 3 & 4 & $15+\mathrm{j} 38.3$ \\
\hline 5 & 2 & 4 & $308.9+\mathrm{j} 937.3$ \\
\hline 6 & 2 & 5 & $150.2+\mathrm{j} 458.6$ \\
\hline 7 & 6 & 12 & $9+\mathrm{j} 18.8$ \\
\hline 8 & 6 & 13 & $24.5+\mathrm{j} 48.2$ \\
\hline 9 & 12 & 13 & $0.4+\mathrm{j} 0.3$ \\
\hline 10 & 13 & 14 & $1.1+\mathrm{j} 2.2$ \\
\hline 11 & 9 & 14 & $48.5+\mathrm{j} 103.2$ \\
\hline 12 & 9 & 10 & $13.7+\mathrm{j} 37.4$ \\
\hline 13 & 6 & 11 & $4.6+\mathrm{j} 9.7$ \\
\hline
\end{tabular}


Optimal Placement of Synchronous Condensers for Power Quality Improvement in Transmission..

\begin{tabular}{|l|l|l|l|}
\hline 14 & 10 & 11 & $6.3+\mathrm{j} 14.8$ \\
\hline 15 & 4 & 5 & $80.3+\mathrm{j} 253.2$ \\
\hline 16 & 4 & 9 & $11.8+\mathrm{j} 32.2$ \\
\hline 17 & 5 & 6 & $186+\mathrm{j} 395.7$ \\
\hline 18 & 7 & 8 & $0+\mathrm{j} 0$ \\
\hline 19 & 7 & 9 & $66+\mathrm{j} 59.7$ \\
\hline 20 & 1 & 5 & $517.6+\mathrm{j} 1053.8$ \\
\hline
\end{tabular}

Table No 8: Power factor without synchronous condenser

\begin{tabular}{|c|c|c|}
\hline From bus ID & To bus ID & $\%$ Power factor \\
\hline \multirow[t]{2}{*}{ Bus 1} & Bus2 & 94.4 \\
\hline & Bus5 & 97.7 \\
\hline \multirow[t]{4}{*}{ Bus 2} & Bus1 & 94.8 \\
\hline & Bus3 & 96.0 \\
\hline & Bus4 & 95.5 \\
\hline & Bus5 & 93.4 \\
\hline \multirow[t]{2}{*}{ Bus 3} & Bus2 & 96.5 \\
\hline & Bus4 & -93.9 \\
\hline \multirow[t]{5}{*}{ Bus 4} & Bus7 & 85.3 \\
\hline & Bus3 & -94.0 \\
\hline & Bus2 & 95.9 \\
\hline & Bus5 & 98.7 \\
\hline & Bus15 & 82.0 \\
\hline \multirow[t]{4}{*}{ Bus 5} & Bus2 & 93.7 \\
\hline & Bus4 & 98.6 \\
\hline & Bus1 & 98.1 \\
\hline & Bus18 & 88.5 \\
\hline \multirow[t]{4}{*}{ Bus 6} & Bus12 & 95.6 \\
\hline & Bus13 & 93.5 \\
\hline & Bus11 & 90.2 \\
\hline & Bus18 & 89.9 \\
\hline \multirow{4}{*}{ Bus 7} & Bus4 & 85.4 \\
\hline & & \\
\hline & Bus17 & 85.4 \\
\hline & Bus16 & 85.4 \\
\hline Bus 8 & Bus17 & 0.0 \\
\hline \multirow[t]{4}{*}{ Bus 9} & Bus14 & 91.8 \\
\hline & Bus10 & 84.6 \\
\hline & Bus15 & 83.3 \\
\hline & Bus16 & 86.5 \\
\hline \multirow[t]{2}{*}{ Bus 10} & Bus9 & 84.6 \\
\hline & Bus11 & 88.9 \\
\hline \multirow[t]{2}{*}{ Bus 11} & Bus6 & 90.1 \\
\hline & Bus10 & 88.9 \\
\hline \multirow[t]{2}{*}{ Bus 12} & Bus6 & 95.6 \\
\hline & Bus13 & 87.9 \\
\hline \multirow[t]{3}{*}{ Bus 13} & Bus6 & 93.6 \\
\hline & Bus12 & 87.9 \\
\hline & Bus14 & 99.6 \\
\hline \multirow[t]{2}{*}{ Bus 14} & Bus13 & 99.6 \\
\hline & Bus9 & 92.2 \\
\hline \multirow[t]{2}{*}{ Bus 15} & Bus9 & 83.3 \\
\hline & Bus4 & 83.3 \\
\hline \multirow[t]{3}{*}{ Bus 16} & Bus9 & 86.5 \\
\hline & Bus7 & 86.5 \\
\hline & Bus17 & 86.5 \\
\hline \multirow[t]{3}{*}{ Bus 17} & Bus8 & 0.0 \\
\hline & Bus16 & 0.0 \\
\hline & Bus7 & 0.0 \\
\hline \multirow[t]{2}{*}{ Bus 18} & Bus6 & 89.5 \\
\hline & Bus5 & 89.5 \\
\hline
\end{tabular}


Optimal Placement of Synchronous Condensers for Power Quality Improvement in Transmission..

\subsection{System with Synchronous Condenser}

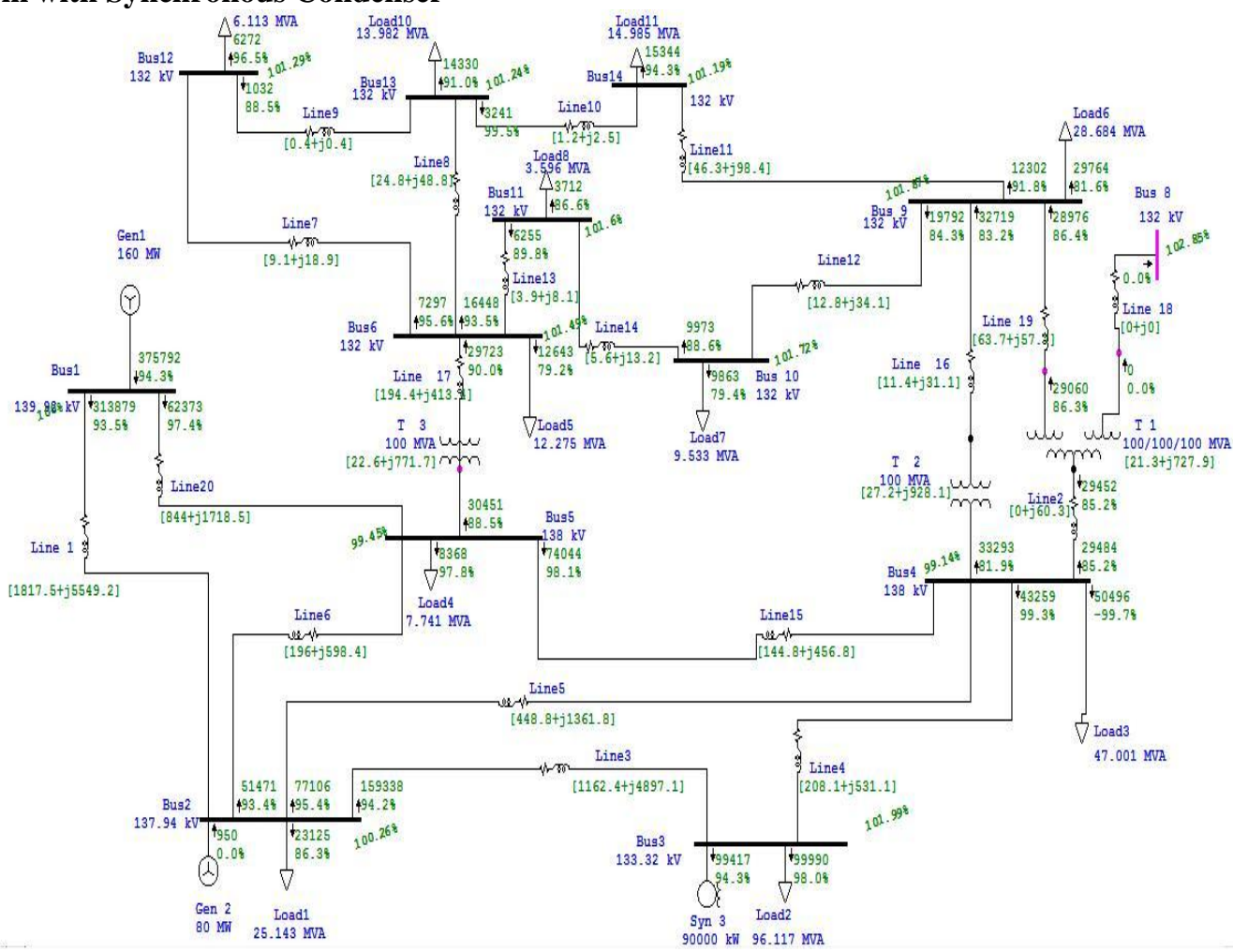

Figure: 5: Power factor for 14 bus system when condenser is at bus 3

Table No 9: Power factor when synchronous condenser is placed at bus 3

\begin{tabular}{|c|c|c|}
\hline From bus ID & To bus ID & \% Power factor \\
\hline \multirow[t]{2}{*}{ Bus 1} & Bus2 & 93.5 \\
\hline & Bus5 & 97.4 \\
\hline \multirow[t]{4}{*}{ Bus 2} & Bus1 & 94.1 \\
\hline & Bus3 & 94.2 \\
\hline & Bus4 & 95.4 \\
\hline & Bus5 & 93.4 \\
\hline \multirow[t]{2}{*}{ Bus 3} & Bus2 & 95.1 \\
\hline & Bus4 & 99.4 \\
\hline \multirow[t]{5}{*}{ Bus 4} & Bus7 & 85.2 \\
\hline & Bus3 & 99.3 \\
\hline & Bus2 & 95.9 \\
\hline & Bus5 & 98.2 \\
\hline & Bus15 & 81.9 \\
\hline \multirow[t]{4}{*}{ Bus 5} & Bus2 & 93.8 \\
\hline & Bus4 & 98.1 \\
\hline & Bus1 & 97.9 \\
\hline & Bus18 & 88.5 \\
\hline \multirow[t]{4}{*}{ Bus 6} & Bus12 & 95.6 \\
\hline & Bus13 & 93.5 \\
\hline & Bus11 & 89.8 \\
\hline & Bus18 & 90.0 \\
\hline \multirow{4}{*}{ Bus 7} & Bus4 & 85.2 \\
\hline & & \\
\hline & Bus17 & 85.2 \\
\hline & Bus16 & 85.2 \\
\hline Bus 8 & Bus17 & 0.0 \\
\hline \multirow[t]{4}{*}{ Bus 9} & Bus14 & 91.8 \\
\hline & Bus10 & 84.3 \\
\hline & Bus15 & 83.2 \\
\hline & Bus16 & 86.4 \\
\hline \multirow[t]{2}{*}{ Bus 10} & Bus9 & 84.3 \\
\hline & Bus11 & 88.6 \\
\hline \multirow[t]{2}{*}{ Bus 11} & Bus6 & 89.8 \\
\hline & Bus10 & 88.6 \\
\hline Bus 12 & Bus6 & 95.7 \\
\hline
\end{tabular}


Optimal Placement of Synchronous Condensers for Power Quality Improvement in Transmission..

\begin{tabular}{|l|l|l|}
\hline & Bus13 & 88.5 \\
\hline Bus 13 & Bus6 & 93.6 \\
\cline { 2 - 3 } & Bus12 & 88.5 \\
\cline { 2 - 3 } & Bus14 & 99.5 \\
\hline \multirow{3}{*}{ Bus 14 } & Bus13 & 99.5 \\
\cline { 2 - 3 } & Bus9 & 92.0 \\
\hline \multirow{3}{*}{ Bus 15 } & Bus9 & 83.1 \\
\cline { 2 - 3 } & Bus4 & 83.1 \\
\hline \multirow{3}{*}{ Bus 16 } & Bus9 & 86.3 \\
\cline { 2 - 3 } & Bus7 & 86.3 \\
\cline { 2 - 3 } & Bus17 & 86.3 \\
\hline \multirow{2}{*}{ Bus 18 } & Bus8 & 0.0 \\
\cline { 2 - 3 } & Bus16 & 0.0 \\
\cline { 2 - 3 } & Bus7 & 0.0 \\
\hline & Bus6 & 89.6 \\
\cline { 2 - 3 } & Bus5 & 89.6 \\
\hline
\end{tabular}

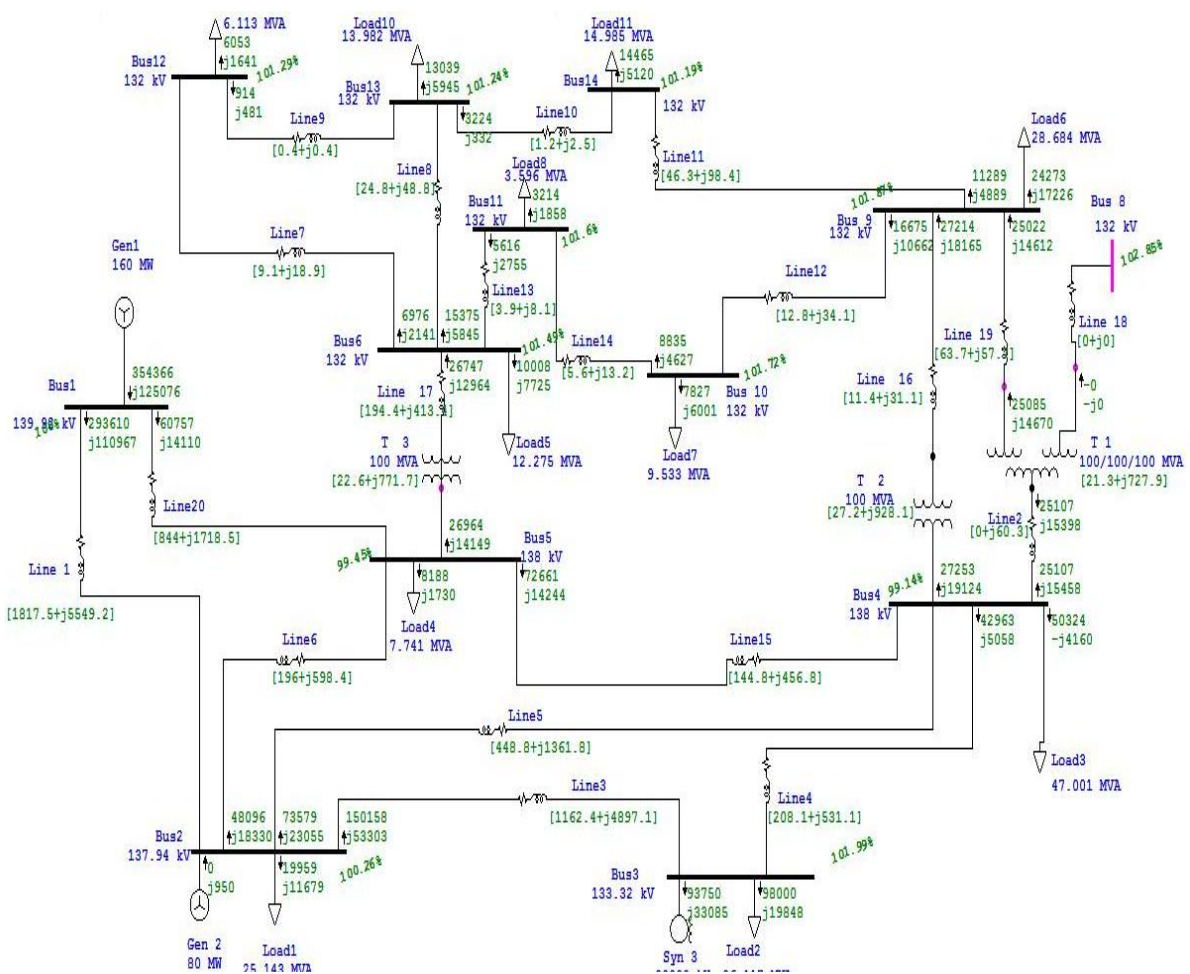

Figure 6: Line losses for 14 bus system when condenser is at bus 3

Table No10: Line losses when synchronous condenser placed at bus 3

\begin{tabular}{|l|l|l|l|}
\hline Line No & From bus & To bus & Losses \\
\hline 1 & & 2 & $1817.5+\mathrm{j} 5549.2$ \\
\hline 2 & 4 & 7 & $0+\mathrm{j} 60.3$ \\
\hline 3 & 2 & 3 & $1162.4+\mathrm{j} 4897.1$ \\
\hline 4 & 3 & 4 & $208.1+\mathrm{j} 531.1$ \\
\hline 5 & 2 & 4 & $448.8+\mathrm{j} 1361.8$ \\
\hline 6 & 2 & 5 & $196+\mathrm{j} 598.4$ \\
\hline 7 & 6 & 12 & $9.1+\mathrm{j} 18.9$ \\
\hline 8 & 6 & 13 & $24.8+\mathrm{j} 48.8$ \\
\hline 9 & 12 & 13 & $0.4+\mathrm{j} 0.4$ \\
\hline 10 & 13 & 14 & $1.2+\mathrm{j} 2.5$ \\
\hline 11 & 9 & 14 & $46.3+\mathrm{j} 98.4$ \\
\hline 12 & 9 & 10 & $12.8+\mathrm{j} 34.1$ \\
\hline 13 & 6 & 11 & $3.9+\mathrm{j} 8.1$ \\
\hline 14 & 10 & 11 & $5.6+\mathrm{j} 13.2$ \\
\hline 15 & 4 & 5 & $144.8+\mathrm{j} 456.8$ \\
\hline 16 & 4 & 9 & $11.4+\mathrm{j} 31.1$ \\
\hline 17 & 5 & 6 & $194.4+\mathrm{j} 413.4$ \\
\hline 18 & 7 & 8 & $0+\mathrm{j} 0$ \\
\hline 19 & 7 & 9 & $63.7+\mathrm{j} 57.7$ \\
\hline 20 & 1 & 5 & $844+\mathrm{j} 1718.5$ \\
\hline
\end{tabular}


Optimal Placement of Synchronous Condensers for Power Quality Improvement in Transmission..

Next change in the values of various parameters will be observed when condenser is placed at various buses in the system for example bus,5,6,7,8,9,10,11,12,13,\&14. Now an optimum place for the condenser will be searched to get best power quality results. Finally a comparison will be made between various parameters of the system to check for best optimum place for the condenser to get best power quality results in the system.

\section{Results and Discussion}

The main focus of this chapter is to achieve and maintain power quality of the transmission system by improving various parameters like reactive power, voltage drop and power factor by placing synchronous condenser at an optimum place in the system through simulation using ETAP PowerStation

\subsection{Results for line losses and power factor}

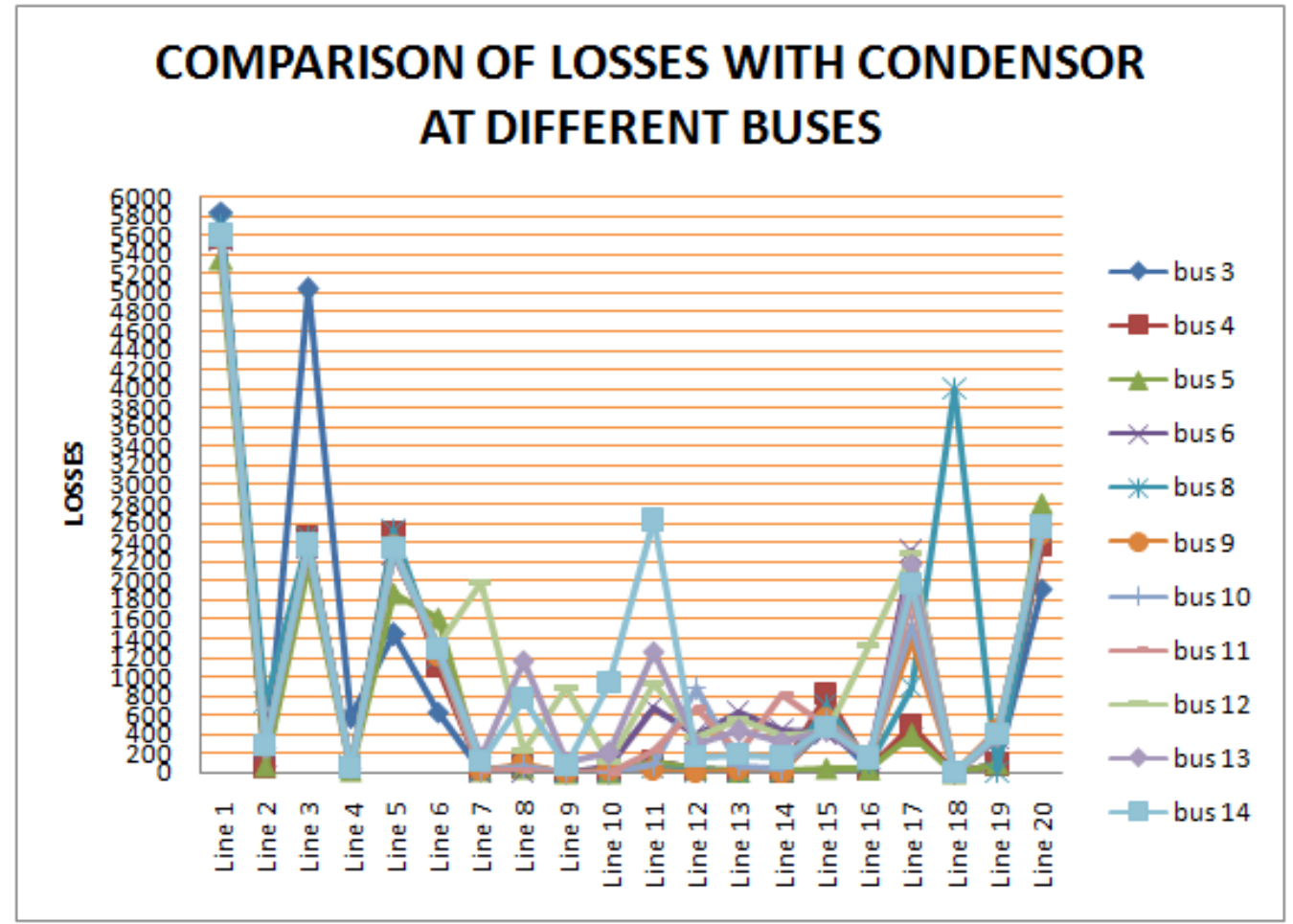

Figure 7: Comparison Of Losses With Condenser At different Buses

\subsection{Graphs for line losses and power factor}

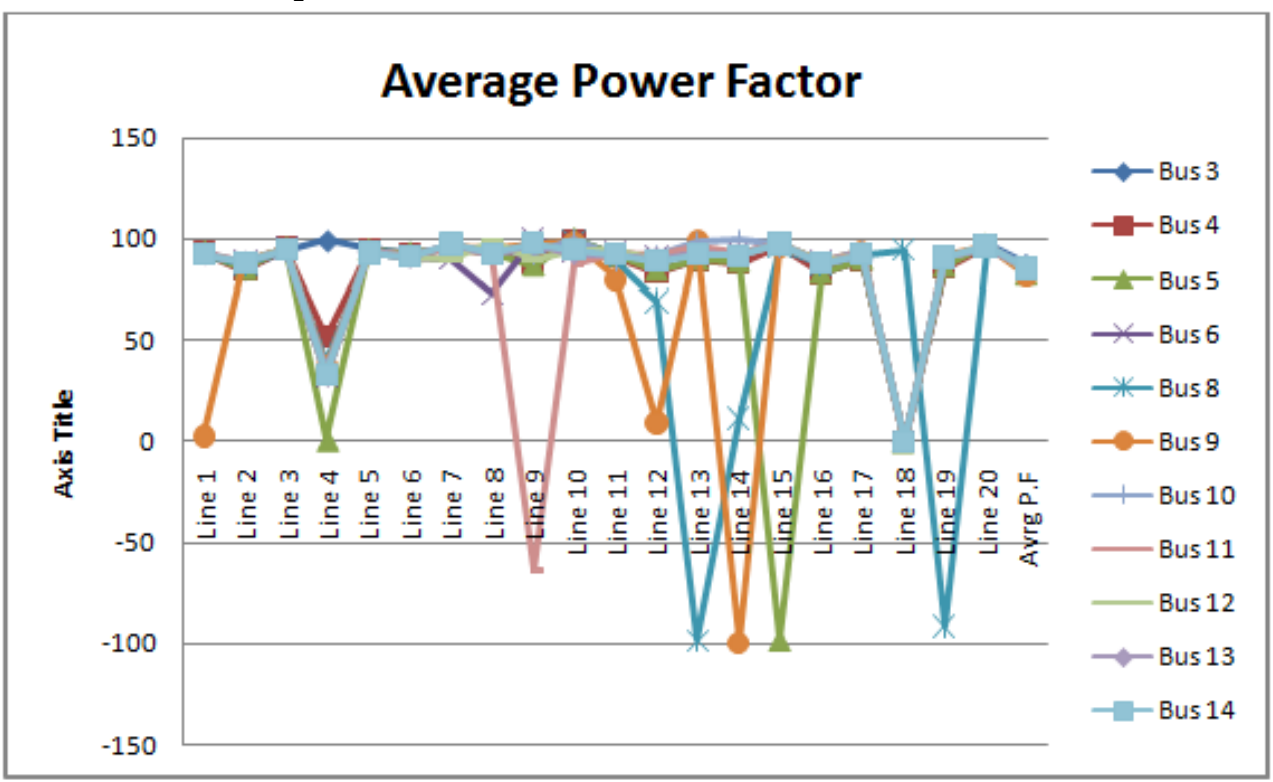

Figure 8: Average Power Factor 
Optimal Placement of Synchronous Condensers for Power Quality Improvement in Transmission..

\subsection{Discussion}

\begin{tabular}{|l|l|l|}
\hline $\begin{array}{l}\text { Parameters } \\
\text { Buses }\end{array}$ & Losses ( kW+ kVAR) & Power factor (\% age) \\
\hline Bus3 & 16783.758 & \\
\hline Bus 5 & 14719.16 & 87.38 \\
\hline
\end{tabular}

From the above table, comparing the results for most optimal results at Bus 3, and Bus 5, we find that line losses at Bus 3 are 16783.75 whereas at bus 5 are 14719.16 . Whereas power factor for bus 3 is 87.38 and at bus 5 is 82.49 .

\section{Conclusions}

As we can infer from the power factor comparison we get the highest power factor when synchronous condenser is placed at bus 3, although losses are minimum when condenser is placed at bus 5, but power factor is lower than that when condenser is placed at bus 3, and also causes overvoltage at bus 3 and bus 8 . Also if condenser is placed at bus 5 a lower power factor leads to inefficient operation. A high power factor helps a power system to make maximum use of generated power. Hence in order to get trade-off between placement of condenser at bus 3 and bus 5, it is more beneficial to place it at bus 3 . This is because:-

It gives highest power factor.

There is minimal overvoltage in any of the buses.

Line losses are low.

Also more accurate results i.e. reduced active and reactive power losses and improved power factor will be obtained if we use more number of synchronous condensers (likely 2 ) in the given 14 bus system.

\section{References}

[1]. Thongkeaw, S., Boonthienthong, M. (2013), "Technique for Voltage Control in Distribution System". International Journal of Electrical, Computer, Energetic, Electronic and Communication Engineering Vol.7, No.10, pp.844-847.

[2]. Tembhurnika, G., Chaudhari, A. (2014) "A Review on Reactive Power Compensation Techniques". Vol.4, Issue.1, ISSN: 22500758 .

[3]. Khaing, M.K.T.(2014)“Power Factor Correction with Synchronous Condenser for Power Quality Improvement in Industrial Load". International Journal of Science and Engineering Applications Vol.3 Issue.3, ISSN: 2319-7560.

[4]. Kothari P.,Nagrath,I J. "Reactive Power Control in Electrical Systems"

[5]. Sekhar, G.A., Reddy, M.P., and Suresh, MCV. (2015)"Ideal Implementation of Device in Shunt for Series Compensated Transmission Line". International Journal of Engineering Trends in Engineering Research, Vol.3, No.6, ISSN: 2250-0758, pp.477482.

[6]. Dideban, M., Ghadimi, N., Ahmadi, M B., andKarimi, M. (2013)“Optimal Location and Sizing of Shunt Capacitors in Distribution System by Considering Different Load Scenarios".Journal Electrical Engineering Technology, Vol.8, No.5, ISSN: 1975-0102, pp.1012-1020.

[7]. Borges, C.L.T., and Falcao, D.M. (2003) "Impact of Distribution Generation Allocation and Sizing on Reliability, Losses and Voltage Profile". Paper accepted for presentation at IEEE Bologna Power Tech Conference ,Bologna Italy,

[8]. Kiran,I.K., and Laxmi,J.(2011) "Shunt versus Series compensation in the improvement of power system performance ”.International Journal of Applied Engineering Research,Vol.2, No.1, ISSN: 0976-4259, pp.28-37.

[9]. Rostamzadeh, M., Valipour, K., Shenava, S.J., Khalilpour, M., and Razmjooy, N.(2012) "Optimal location and capacity of multi-distributed generation for loss reduction and voltage profile improvement using imperialist competitive algorithm" .Artificial Intelligence Research ,Vol.1, No.2, ISSN: 1927-6982, pp.56-66.

[10]. K. R. C. Mamandur, R. D. Chenoweth, "Optimal control of reactive power flow for improvements in voltage profiles and for real power loss minimization" IEEE Transactions on Power Apparatus and Systems, Vol. PAS-I1O, No. 7 July 1981,page no. 31853194

[11]. Paul M. Anderson, A. A. Fouad,” Power System Control and Stability", IEEE press power engineering series.

[12]. S. RamaIyer, R. Ramachandran, S. Hariharan, New technique for optimal reactive power allocation for loss minimization in power system.

[13]. J. Carpentier, Optimum power flow—a survey, Int. J. Electric. Power Energy Syst. 1 (1) (1979) 3-15.

[14]. M.A. Kashem, V. Ganapathy, G.B. Jasmon, M.I. Buhari.A Novel Method for Loss Minimization in Distribution Networks. proceeding of International Conference on Electric Utility Deregulation and Restructuring and Power Technologies. 2000.

[15]. R.A. Jabr, B.C. Pal, Ordinal optimization approach for locating and sizing of distributed generation, IET generation, Transm. Distrib. 2009; 8: 713-723.

[16]. X.Q. Ding, J.H. Wu, F. Zhao. Optimal location and capacity of distributed generation based on scenario probability, in: Proceedings of the International Conference on Sustainable Power Generation and Supply. Nanjing. 2009; 1-5.

[17]. Jen-HaoTeng.A Direct Approach for Distribution System Load Flow Solutions. 2003; 18(3): 882-887.

[18]. HadiSaadat, Power System Analysis, WCB McGraw Hill, 1999. 